\title{
Avances y desafíos del desarrollo sostenible en Uruguay y sus implicancias territoriales: Una mirada a la localización de los ODS en Tacuarembó
}

\author{
Amalia Margarita Stuhldreher \\ Universidad de la República - Montevideo - Uruguai \\ ORCID: http://orcid.org/0000-0002-0918-3099
}

\section{Resumen}

Este trabajo recoge los primeros resultados de un proyecto de Espacio de Formación Integral (EFI) de la Universidad de la República (UDELAR) respecto a avances y desafíos para la localización de los Objetivos de Desarrollo Sostenible (ODS) en Uruguay, a partir de una mirada territorial focalizada en el departamento de Tacuarembó y su contexto regional en el Noreste del país, caracterizados históricamente por un rezago relativo en materia de desarrollo. Considerando la evolución de la conceptualización del desarrollo y adoptando una estrategia metodológica cualitativa, el trabajo tematiza acciones, posibilidades y desafíos actuales de la provisión de bienes públicos en dimensiones esenciales del desarrollo humano sostenible. El análisis focaliza las percepciones de los actores territoriales agrupados en la Mesa de Desarrollo Local (MDL) respecto al proceso de localización de los ODS 8 y 13, así como respecto a la necesidad a futuro de fortalecer la planificación y establecer mecanismos de gobernanza para el logro de dichas metasesumen letra candara tam 11 normal

Palabras clave: Desarrollo territorial. Localización ODS. Región Noreste del Uruguay.

\section{Avanços e desafios do desenvolvimento sustentável no Uruguai y suas implicações territoriais: Um olhar a localização dos ODS em Tacuarembó}

Resumo

Este trabalho apresenta os primeiros resultados de um projeto vinculado a um Espaço de Formação Integral (EFI) da Universidade de la República (UDELAR) relativo aos avanços e desafios para a localização dos Objetivos de Desenvolvimento Sustentável (ODS) da Agenda 2030 no Uruguai, a partir de um olhar territorial focalizado no departamento de Tacuarembó e seu contexto regional no Nordeste do país, caracterizados históricamente por um atraso relativo em matéria de desenvolvimento. Considerando a evolução da conceituação teórica do desenvolvimento e adotando uma estratégia metodológica qualitativa, o trabalho tematiza ações, possibilidades e desafios atuais da provisão de bens públicos em dimensões essenciais de desenvolvimento humano sustentável. A análise focaliza as percepções dos atores territoriais agrupados na Mesa de Desenvolvimento Local $(\mathrm{MDL})$ relativo ao processo de localização dos ODS 8 e 13 em Tacuarembó e à necessidade 
de no futuro fortalecer a planificação, estabelecendo mecanismos governamentais para lograr alcançar esses objetivos.

Palavras-chave: Desenvolvimento territorial. Localização ODS. Region Nordeste no Uruguai.

\section{Progress and challenges of sustainable development in Uruguay and its territorial implications. A look at the localization of the SDGs in Tacuarembó}

\section{Abstract}

This work presents some first results of a project related to an 'Integral Training Area' (EFI for its acronym in Spanish) at the University of the Republic (UDELAR) regarding progress and challenges related to the 2030 Agenda and Sustainable Development Development Goals (SDGs) localization process in Uruguay. Based on a territorial approach, the paper focuses on the situation of the Department of Tacuarembó and its regional context in the Northeast Region of the country, historically characterized by a relative lag in its development. Considering the evolution of the theoretical conceptualization of development and adopting a qualitative methodological strategy, the work addresses current actions, possibilities and challenges related to the provision of public goods in essential dimensions of human sustainable development. Taking account of the perceptions of territorial actors grouped in the Local Development Board (MDL for its acronym in Spanish), this research assesses the localization process of SDGs 8 and 13 in Tacuarembó, as well as the future challenges concerning strengthening planning and establishing governance mechanisms in order to achieve these goals.

Keywords: Territorial development. SDGs localization. Uruguay's Northeast Region.

\section{Introducción}

Mientras que algunos autores como Sanahuja (2016) entienden que la definición de la Agenda 2030 de Desarrollo Sostenible y las metas materializadas en los ODS expresan una evolución en la concepción de desarrollo (superando la visión tradicional Norte-Sur y apuntando a un pacto global para el desarrollo), persiste la necesidad de la contextualización de las metas en ámbitos territoriales específicos, donde el devenir de los procesos de desarrollo como construcción social es afectado por dinámicas de concertación pero también de conflictos y disputas entre actores diversos, con lógicas y visiones no siempre concordantes. Teniendo en cuenta lo anterior, desde una perspectiva multinivel este trabajo considera la vinculación entre el planteo de los ODS a nivel global y la necesidad de traducción esos ODS en las "agendas locales", incorporando elementos de la dimensión territorial del desarrollo. A la vez, también se toman en cuenta las políticas nacionales, que cumplen un rol fundamental al constituir el ámbito de definiciones del marco jurídico-legal y de los impulsos de programas y acciones a nivel del país, asignando recursos indispensables. De hecho, como señala Ojeda Medina (2020), hasta ahora los Estados han sido la principal fuente planificación, financiación y ejecución de diferentes formas de Cooperación Internacional para el Desarrollo (CID), siendo los principales protagonistas de los espacios de concertación política y técnica en materia de cooperación. En contraste, los análisis académicos durante largo tempo han relegado a un segundo plano a los gobiernos locales y regionales, con escaso reconocimiento y visibilidad de sus prácticas, aunque hayan sido convocados a contribuir con la implementación de la Agenda 2030 y los ODS. 
Este trabajo parte del supuesto que gran parte el éxito (y con ello gran parte de la responsabilidad en la consecución de las metas) dependerá de dinámicas de concertación multinivel, por lo que además del rol de los gobiernos locales y regionales, también debe profundizarse el análisis de las contribuciones de otros actores de la sociedad civil, del ámbito privado y de la academia a nivel territorial. En ese sentido, se recogen aquí los hallazgos de diferentes relevamientos efectuados en el departamento de Tacuarembó. En particular se analizan los primeros resultados de un proyecto de Espacio de Formación Integral (EFI) ${ }^{1}$ titulado "Los problemas del desarrollo tras los Objetivos del Milenio: La agenda 2030 del desarrollo sostenible en clave territorial", que fue aprobado en el marco del Llamado 2019 de la Unidad de Extensión y Actividades en el Medio de la Facultad de Ciencias Sociales de la Universidad de la República (UDELAR) para apoyos financieros a EFIs. El proyecto inició sus actividades durante el segundo semestre de 2019 con estudiantes de la Tecnicatura en Desarrollo (TED) de la sede Tacuarembó de la UDELAR, con la orientación de docentes del Instituto de Desarrollo Sostenible, Innovación e Inclusión Social (IDIIS) y de la Unidad de Extensión de dicha sede, así como del Programa de Estudios Internacionales (PEI) de la Facultad de Ciencias Sociales. El objetivo planteado fue contribuir al conocimiento y problematización de Ios ODS a nivel local, a través de actividades que incluyeron instancia de formación y sensibilización sobre la temática, así como talleres con los referentes de las instituciones que integran la Mesa de Desarrollo Local (MDL) del departamento de Tacuarembó.

La elección de la MDL como interlocutor del mencionado EFI se vinculó al carácter de dicho espacio de concertación y articulación local, así como sus cometidos en materia de desarrollo. Para dicha decisión se partió del entendido que los avances en la implementación de los ODS en el país dependerán en gran medida de la capacidad de los territorios de lograr una "traducción local" adecuada de aquellos objetivos y metas planteados a nivel global. En ese sentido, siguiendo a Farinós Dasí, Monteserín y Escribano (2018) puede entenderse a la cooperación territorial como un principio y requisito necesario para un mejor desarrollo local y regionalonal, donde resulta de suma importancia tanto el diseño y objetivos de las políticas públicas, como la manera en que son proyectada y sobre todo implementadas. En esa línea, como señalan Serra Borsatto, Antunes Junior y Ferreira Sousa-Esquerdo (2020), en un territorio pueden coexistir y actuar diferentes arreglos institucionales, cada cual con sus agendas para el desarrollo, por lo que resulta interesante relevar las relaciones entre los agentes públicos, privados y actores sociales distribuidos en dichos arreglos específicos para poder analizar la gobernanza territorial. En este caso, se consideró significativo el accionar de um esquema de gobernanza como el de la MDL, donde se articulan diferentes niveles de gobierno y que incluyen un espectro amplio de actores público-institucionales,

\footnotetext{
${ }^{1}$ En la UDELAR se designa como Espacio de Formación Integral (EFI) a propuestas pedagógicas que apuntan a integrar las tres funciones universitarias (enseñanza, investigación y extensión): dichas iniciativas se basan en un núcleo de enseñanza desde el cual se procura fomentar la perspectiva interdisciplinaria como forma de aproximación a la realidad social. Un objetivo central ha sido impulsar la transformación de la enseñanza, en especial a través del fortalecimiento de la vinculación con el medio con abordajes pedagógicos innovadores.
} 
de la sociedad civil y del sector privado. Como contextualización cabe mencionar que la MDL surge en 2013 por impulso de la Dirección Nacional de Artesanías, Pequeñas y Medianas Empresas (DINAPYME) que pertenece al Ministerio de Industria, Energía y Minería (MIEM), encontrando el apoyo de diversas instituciones públicas y privadas departamentales y organismos nacionales con representación territorial en el distrito de Tacuarembó.

En el espacio de la MDL converge instituciones tales como el Programa Uruguay Más Cerca (UMC) de la Oficina de Planificación y Presupuesto (OPP), la representación regional de la DINAPYME, el Ministerio de Desarrollo Social (MIDES), el Ministerio de Ganadería, Agricultura y Pesca (MGAP), el Instituto Nacional de Empleo y Formación Profesional (INEFOP), la representación de los trabajadores (PIT-CNT), el Centro de Competitividad Empresarial (CCE), el Instituto Nacional de Investigación Agropecuaria (INIA), la sede Tacuarembó de la UDELAR, la Dirección de Proyectos de Desarrollo y Medioambiente (PRODEMA) de la Intendencia Departamental de Tacuarembó (IDT), la Asociación Empresarial de Tacuarembó (AET), la Agencia de Desarrollo de Tacuarembó (ADT), la ONG Centro Latinoamericano de Economía Humana (CLAEH) y el Foro de la Madera. En cuanto a sus fines, en un proceso de deliberación interinstitucional la MDL logró definir un Plan Estratégico 2015-2017 para la MDL, cuya misión se definió como:

contribuir al desarrollo sostenible del Departamento con inclusión social y equilibrio ambiental, a través de la articulación de los esfuerzos de los actores públicos y privados para aportar a la construcción de políticas y la viabilización de proyectos que potencien las capacidades locales de desarrollo de las cadenas productivas, la competitividad empresarial particularmente de las PYMES - y el posicionamiento territorial (MDL, 2015, p. 5).

El presente trabajo apunta a una valoración cualitativa de los avances y desafíos de la localización de los ODS en un departamento como el de Tacuarembó, inserto en una región con rezagos históricos en materia de desarrollo, lo que también condiciona sus posibilidades de evolución futura. Dicha valoración apunta a una mejor comprensión de las dinámicas tanto a nivel individual de instituciones así como las dinámicas colectivas que se plantean entre los participantes de la MDL. De esa forma, el objetivo central radica en establecer los rasgos particulares del caso en términos de su 'unicidad' (STAKE, 1999), sin pretender su generalización ni extrapolación, aunque sí se busca ilustrar y discutir los alcances y posibilidades de surgen en un proceso concreto de localización de las metas planteadas a nivel global. Las interacciones implícitas y explícitas en el proceso representan un aprendizaje en clave local que puede resultar de interés para la consideración de otros casos prácticos. Por otra parte, el análisis de la experiencia también busca aportar a la discusión sustantiva, así como reflexión teórico-metodológica en la temática de la localización de los ODS, donde existe todavía escasa acumulación.

Como punto de partida del análisis se explicitan en primer término algunos elementos centrales de la evolución teórico-conceptual de la noción de desarrollo que conduce al surgimiento de los ODS. Se considera asimismo el proceso de deliberación intergubernamental que acompañó la elaboración de la Agenda 2015 y el posicionamiento América Latina y de Uruguay en dicho proceso y se mencionan algunos antecedentes en el relevamiento de la localización de los ODS en el territorio considerado. En segundo lugar, se consideran las heterogeneidades 
estructurales y la polarización existente entre la capital y el Interior del Uruguay, efectuando una breve caracterización del departamento de Tacuarembó. En tercer lugar se presenta la estrategia metodológica que guía el trabajo. En cuarto lugar se presentan los principales hallazgos del EFI, focalizando en el ODS 8 (Trabajo decente y crecimiento económico) y en el ODS 13 (Acción por el clima). Finalmente se discuten algunas implicancias de los resultados del ejercicio en la proyección futura del territorio de Tacuarembó.

\section{Contextualización teórico-conceptual y surgimiento de los ODS}

Para una comprensión cabal de las implicancias de los actuales ODS es preciso remontarse en el tiempo y tener en cuenta la evolución de los enfoques sobre desarrollo durante varias décadas. En ese sentido, autores como Griffin (2001) y Bertoni et al. (2011) plantean que después de una etapa tras Segunda Guerra Mundial donde los enfoques teóricos atribuyeron especial importancia al crecimiento económico al momento de pensar el desarrollo de las comunidades (ROSTOW, 1960; KUZNETS, 1971), desde los años '60 y 70' del siglo XX emerge una fuerte crítica a la concepción economicista anterior, donde entre otras cosas se subraya la especificidad de los desafíos en términos de desarrollo de las diferentes sociedades, así como se postula la necesidad de explicitar la dimensión normativa del desarrollo (SEERS, 1970). Recogiendo los aportes de Seers, en América Latina los trabajos de Manfred Max-Neef (1993) y otros colegas proponían la categoría de desarrollo "a escala humana". Desde una perspectiva estructuralista, también la Comisión Económica para América Latina (CEPAL) efectúa contribuciones significativas a la discusión del desarrollo de la región.

En los '90, el Programa de las Naciones Unidas para el Desarrollo (PNUD) inicia la publicación de la serie de Informe sobre Desarrollo Humano a partir de las conceptualizaciones de Amartya Sen (2000) y del paquistaní Mahbub ul Haq (1996). Se consolida así una acepción del desarrollo donde el ser humano ocupa un lugar central como actor principal, por lo que el desarrollo humano pasó así a entenderse como un proceso de ampliación de las opciones de las personas para construir sus vidas en sociedad. Progresivamente este enfoque procuró incorporar en forma coherente la dimensión medioambiental como componente medular del desarrollo a partir de los debates surgidos en los '70 (MEADOWS ET AL., 1972) y que cobraron fuerza desde el Informe Brundtland (1987). Así, el denominado paradigma del desarrollo humano sostenible se convirtió en referencia central de los estudios del desarrollo, más allá de los debates y las propuestas de ajustes que suscitó (BERTONI ET AL., 2011: 29-30; EVANS; HELLER, 2015; AROCENA, 2017).

Esta evolución esbozada esquemáticamente no implica claramente la existencia de un consenso absoluto respecto a la conceptualización del desarrollo. En ese sentido, Rivero Illa (2014: 15 y ss.) subraya la complejidad de la temática ya que las nuevas perspectivas de desarrollo no reemplazaron las visiones anteriores, sino que frecuentemente surgieron superposiciones donde se mantuvieron muchos elementos de los paradigmas anteriores. El resultado fue una acumulación sucesiva de visiones no siempre concordantes.

Pese a esas restricciones, la conjunción de los elementos conceptuales esbozados anteriormente marcó la definición de la agenda de los Objetivos del 
Milenio (ODM) desde el 2000 hasta 2015, donde la concepción de desarrollo humano con perspectiva de derechos tuvo una impronta decisiva, sin la dimensión económica ni la medioambiental fueran consideradas con fuerza. Sus críticos enfatizan su carácter pescriptivo dirigido a los países en desarrollo, sin aspiraciones para convertirse en una hoja de ruta global hacia el desarrollo (BÁRCENA 2015: 130). A la vez, a causa de cambios profundos del sistema internacional, para comienzos del siglo XXI los países de América Latina y el Caribe enfrentaban complejos desafíos en materia de desarrollo que no encontraba tantas coincidencias con la agenda de los ODM definida por las Naciones Unidas: varios países de la región incluyendo a Uruguay dejaban atrás algunos problemas clásicos del desarrollo latinoamericano para confrontar desafíos característicos de los países de renta media, con sus consabidas "trampas" (CEPAL, 2010; 2012), mientras que se veían afectados por problemáticas de orden global como el cambio climático, la seguridad energética, la estabilidad financiera o los mercados alimentarios.

Más allá del reduccionismo que marcó los ocho ODM, se instaló progresivamente en la comunidad internacional la necesidad de monitorear logros relevantes para el bienestar de las personas con metas plausibles de verificación y comunicación. Se entendía que esto facilitaría la evaluación de las políticas públicas en función de resultados, fomentando aprendizajes respecto al diseño y manejo de instrumentos de monitoreo ( $\mathrm{AUCl}, 2013: 3)$. La transición de los ODM se dio a través de la labor del Grupo Abierto de Trabajo instaurado luego de la Cumbre Río+20, que presenta la propuesta de los ODS para ser discutida por la Asamblea General de las Naciones Unidas en septiembre de 2014 tras un proceso consultivo sobre la nueva Agenda de Desarrollo y Panel de Expertos de Alto Nivel representativo de todas las regiones. En el proceso de discusión, la CEPAL procuró aportar un "perfil de acción” regional remarcando tópicos como el ingreso por habitante, la desigualdad, la pobreza, la inversión y el ahorro, la productividad y la innovación, la infraestructura, la educación, la salud, la fiscalidad, el género y el medioambiente. En Uruguay la Agencia Uruguaya de Cooperación Internacional $(\mathrm{AUCl})$ y el Ministerio de Relaciones Exteriores fungieron como articuladores de posicione, recogiendo las visiones de organismos del Estado, organizaciones de la sociedad civil, sector privado y academia, donde las prioridades identificadas fueron la erradicación de la pobreza, manteniendo al mismo tiempo el enfoque de derechos, género, infancia, salud, seguridad alimentaria, crecimiento económico, empleo, infraestructura, educación, agua y saneamiento, energía, desigualdad, medio ambiente y consumo responsable.

Tras la definición de los ODS Uruguay se comprometió, junto con otros 43 países, a presentar en 2017 ante el Foro Político de Alto Nivel de la ONU el primer Reporte Nacional Voluntario (VNR por sus siglas en inglés) relativo a los ODS, como forma de cumplir con el mecanismo periódico para el seguimiento de la Agenda 2030(PRESIDENCIA DE LA REPÚBLICA, 2017). Desde entonces el país ha cumplido con los compromisos de reportes anuales de carácter voluntario.

Desde los gobiernos locales y regionales existió preocupación para que se incluyeran sus visiones, logrando establecer un ODS específico relativo a Ciudades Sostenibles y Asentamientos Urbanos (ODS 11) y creando en 2013 un grupo de tareas (Global Taskforce) de Gobiernos Locales y Regionales, para coordinar las redes internacionales de gobiernos locales. Se entiende que aunque los ODS sean 
globales, sus implicancias tocan fuertemente las áreas de competencia de los gobiernos locales y regionales, constituyendo el lugar clave para la consecución de las metas.

La guía elaborada por este grupo de tareas junto con el PNUD y ONU Habitat para la localización de los ODS constituye una de las referencias en Uruguay en esta temática. Con el concepto de 'localización' se denomina al proceso que tiene en cuenta los contextos subnacionales en el logro de la Agenda 2030, entendiendo que dicha localización se refiere a la forma en la que los gobiernos locales y regionales pueden dar apoyo para alcanzar los ODS por medio de la acción "desde abajo", así como al marco que los ODS pueden ofrecer para la política de desarrollo local. Según este enfoque, por tratarse del nivel de gobierno más cercano a la población, los gobiernos locales y regionales se encuentran estratégicamente posicionados para fomentar la conciencia sobre el significado de los ODS y su relevancia para las comunidades locales (GLOBAL TASKFORCE, 2016). A nivel académico existen ya algunos análisis sobre experiencias de localización de ODS en América Latina que confirman la importancia del rol de los gobiernos locales y regionales de cara a la Agenda 2030 a través de la Cooperación Sur-Sur- (CSS) y la Cooperación Triangular (CT) (OJEDA MEDINA, 2020).

Dentro de los esfuerzos de localización de los ODS en Uruguay debe mencionarse la realización durante 2019 de una serie de Informes Diagnósticos para los diferentes departamentos del país, con el apoyo de la OPP y el PNUD, lo que también incluye a Tacuarembó (OPP/PNUD, 2019). Dicho diagnóstico de planes, políticas y acciones del nivel departamental y su asociación con los ODS aplicó la herramienta RIA (Rapid Integrated Assessment) como mecanismo relevante para la localización de la Agenda 2030. Con ese instrumentario se efectuó un mapeo de los ODS y sus metas estableciendo una vinculación con las prioridades nacionales/subnacionales, tomando como fuentes de información principales el Mirador Ciudadano de OPP, un Informe de la IDT para los ODS, así como páginas web de la IDT, los Ministerios y OPP y sistematizando la información en tres categorías que definen las acciones implementadas por el gobierno departamental: planes, proyectos o acciones.

El diagnóstico identifica 209 iniciativas que abarcan 267 vinculaciones ente las actividades de la IDT y los ODS. ${ }^{2}$ El Informe permite agrupar a los objetivos en tres conjuntos: i) ODS altamente reflejados en las iniciativas departamentales, ii) ODS medianamente reflejados en dichas iniciativas y iii) ODS escasamente contemplados. Según este relevamiento, los ODS 4 (Educación de calidad), 8 (Trabajo decente y crecimiento económico), 9 (Industria, innovación e infraestructura) y 11 (Ciudades comunidades sostenibles) corresponden a la categoría de ODS altamente reflejados en las iniciativas departamentales, mientras que el ODS (Salud y bienestar) es incluido en la categoría de ODS medianamente reflejados. Finalmente, en la categoría de objetivos escasamente contemplados se encuentran los ODS 1 (Fin de la pobreza), 2 (Hambre cero), 5 (Igualdad de género), 6 (Agua limpia y saneamiento), 7 (Energía asequible y no contaminante), 10

\footnotetext{
${ }^{2}$ La vinculación no implica una única correspondencia: pueden existir iniciativas que se vinculen a más de un ODS, así como algunas iniciativas departamentales pueden incluir varias acciones, como los planes o políticas.
} 
(Reducción de las desigualdades), 12 (Producción y consumo responsables), 13 (Acción por el clima), 14 (Flota y fauna acuáticas), 15 (Vida de ecosistemas terrestres) y 16 (Paz, justicia e instituciones sólidas).

\section{Uruguay y la heterogeneidade de sus territórios como desafio a la consecución de los ODS}

Dentro de la región latino-americana, Uruguay presenta indicadores de desarrollo relativo que lo posicionan favorablemente. Según datos del Banco Mundial publicados en julio de 2019, el producto interno bruto (PIB) per cápita en 2018 en Uruguay fue de U\$S 15.650, seguido por Chile con U\$S 14.670, lo que los categorizaba como países de ingresos altos. ${ }^{3}$ Por otra parte, en una comparación global Uruguay también se posiciona destacadamente en materia del Índice de Desarrollo Humano (IDH): en 2017 el país alcanzaba la posición 55 en el ranking de 189 países que presenta PNUD, con un valor del IDH de 0.804 . Sin embargo, según datos del PNUD cuando este valor se ajusta por desigualdad, el IDH cae a 0,689, o que representa una pérdida del $14,3 \%$, debido a la desigualdad en la distribución del desarrollo humano. Entre otros factores, la heterogeneidad territorial representa un aspecto que hace a dicha desigualdad. En ese sentido, las últimas mediciones disponibles en materia de IDH elaboradas por el Observatorio Territorial del Uruguay (OTU) a partir de los datos del Banco Central del Uruguay (BCU), el Banco Mundial y el Instituto Nacional de Estadísticas (INE) ponen de manifiesto la situación del departamento de Tacuarembó, así como de los otros departamentos de la región Noreste en 2017: dentro del ranking de los diecinueve departamentos del país, Tacuarembó presenta un IDH de 0,776, mientras que Rivera alcanza un IDH 0,765 y Cerro Largo de 0,783. En comparación el departamento de Montevideo (capital del país), se posiciona con 0,841 (OTU/OPP, 2018). ${ }^{4}$

Considerando datos provenientes del Censo de 2011 y de la aplicación de la metodología del cálculo de las Necesidades Básicas Insatisfechas (NBI), el Atlas Sociodemográfico y de la Desigualdad del Uruguay (CALVO, 2013: 31-32) posiciona a Tacuarembó junto con otros departamentos del Norte como los territorios que concentran los porcentajes más altos de población con al menos una necesidad básica insatisfecha: Rivera (45,4\%), Tacuarembó $(45,2 \%)$ y Cerro Largo (44,8\%), a los que se suman Artigas (54,4\%) y Salto (49,4\%).

\footnotetext{
${ }^{3}$ Por contar con ingresos per cápita por debajo de los U\$S 12.375 países como Argentina, Colombia, Costa Rica, México, Brasil, Perú, Ecuador, Paraguay, Belice y Guatemala se ubicaron en una segunda categoría correspondiente a países con ingreso medio-alto. Por su parte, El Salvador, Bolivia, Honduras y Nicaragua se ubicaron en el tercer conjunto según esta categorización, calificando como países de ingresos medios-bajos. Ningún país de la región fue incluido en la lista de ingresos bajos en esta edición 2019.

${ }^{4}$ Por contar con ingresos per cápita por debajo de los U\$S 12.375 países como Argentina, Colombia, Costa Rica, México, Brasil, Perú, Ecuador, Paraguay, Belice y Guatemala se ubicaron en una segunda categoría correspondiente a países con ingreso medio-alto. Por su parte, El Salvador, Bolivia, Honduras y Nicaragua se ubicaron en el tercer conjunto según esta categorización, calificando como países de ingresos medios-bajos. Ningún país de la región fue incluido en la lista de ingresos bajos en esta edición 2019.
} 
Considerando la necesidad de contemplar la multidimensionalidad de los procesos de desarrollo así como las implicancias de la inserción de los territorios en una determinada región, es interesante considerar en esta caracterización el Índice de Desarrollo Regional y Especialización Productiva (IDERE) elaborado por la Agencia Nacional de Desarrollo (ANDE) y el Instituto de Economía (IECON) de la Facultad de Ciencias Económicas de la UDELAR y que toma como referencia la evolución desde 2009 a 2016. Dicho índice incluye múltiples dimensiones: (1) Educación; (2) Salud; (3) Bienestar y Cohesión Socioeconómica; 4) Economía; (5) Conectividad; (6) Seguridad; (7) Calidad Institucional Sub-nacional y (8) Ambiente, ${ }^{5}$ cuya ponderación permite también contextualizar el territorio analizado en este trabajo: dentro de los diecinueve departamentos del país, Tacuarembó alcanza la decimocuarta posición, con un valor de IDERE de 0,506. Se ubica así por debajo del promedio nacional del IDERE (cuyo valor es de 0,537), alcanzando una tasa de crecimiento del indicador del $23 \%$ en la etapa entre 2009 y 2016, por lo que muestra una evolución superior a la media nacional (RODRÍGUEZ MIRANDA; MARTÍNEZ RODRÍGUEZ, 2019a). Rivera presenta un valor de IDERE de 0,489, ubicándose en el decimosexto puesto, por debajo del promedio nacional del IDERE aunque con un crecimiento de este indicador superior al $23 \%$ en el período señalado, superior a la media nacional (RODRÍGUEZ MIRANDA; MARTÍNEZ RODRÍGUEZ, 2019b). Por su parte Cerro Largo muestra un valor de IDERE de 0,440 y se ubica con ello en el último lugar de todos los departamentos del país, aunque ha experimentado una tasa de crecimiento de 21.69\% del IDERE entre 2009 y 2016 (RODRÍGUEZ MIRANDA; MARTÍNEZ RODRÍGUEZ, 2019c).

\footnotetext{
${ }^{5}$ El IDERE apunta a medir el desarrollo a nivel territorial desde una perspectiva multidimensional utilizando una medida geométrica de índices normalizados entre o y 1 (donde o expresa el desarrollo mínimo y 1 el máximo). Esto permite analizar trayectorias y asimetrías de dimensiones consideradas críticas en el desarrollo de las personas, sistematizadas según las regiones que habitan, identificando las desigualdades territoriales y brechas existentes.
} 
Figura 1: Contextualización regional del departamento de Tacuarembó

\author{
El departamento de Tacuarembó \\ en el contexto regional del Noreste
}

\author{
Referencias \\ 1) Índice de Desarrollo Humano (IDH) \\ 2) Necesidades Básicas Insatisfechas (NBI) \\ 3) Índice de Desarrollo Regional (IDERE)
}

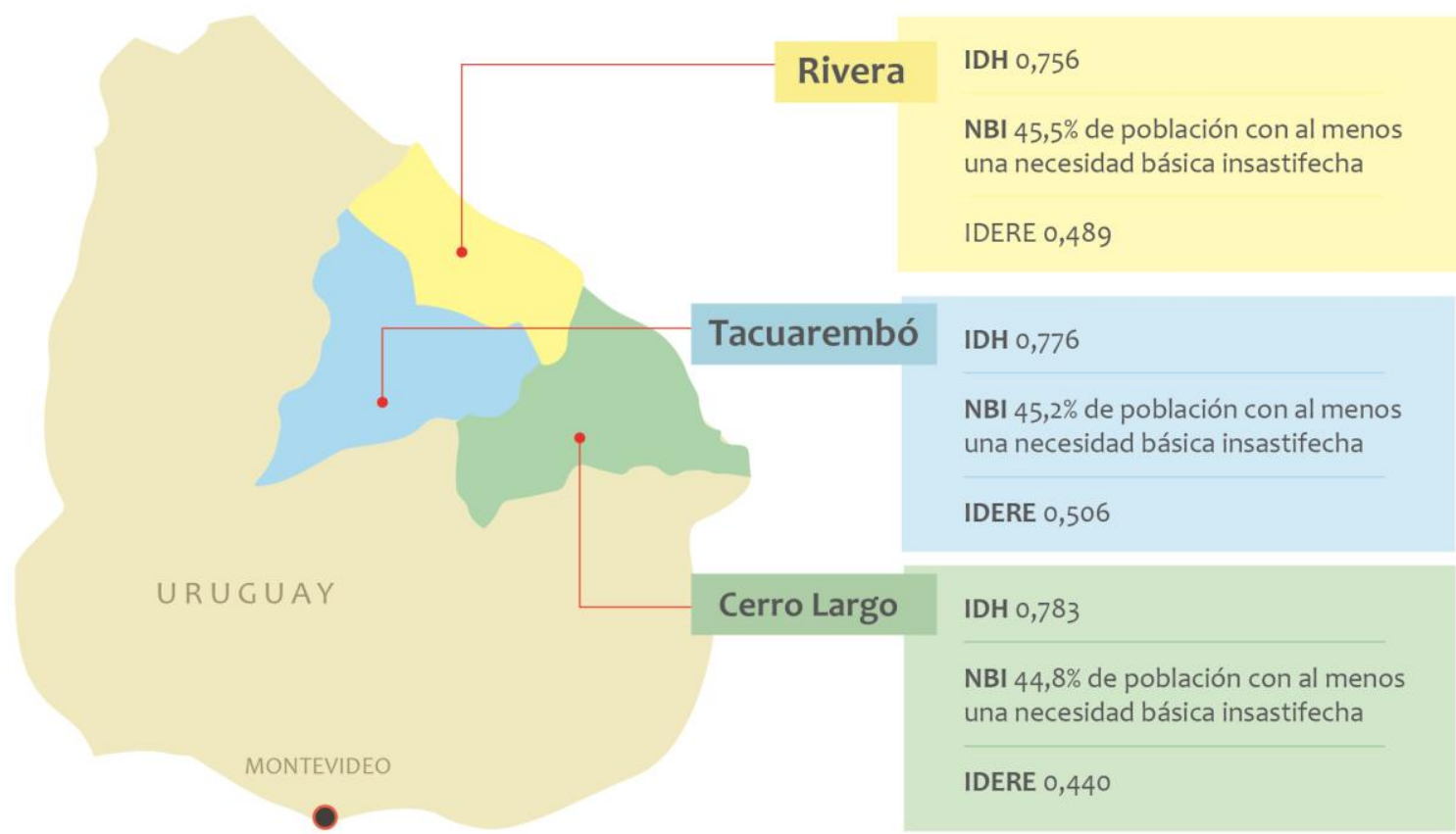

Elaboración propia a partir de datos de OTU/OPP (2018), CALVO (2013) y RODRíGUEZ MIRANDA; MARTINEZ RODRÍGUEZ (2019a; 2019b y 2019c).

En función de los rasgos que caracterizan al departamento de Tacuarembó para el EFI que analiza en este trabajo se priorizó el abordaje de dos ODS específicos para esta etapa, que se encuentran entre los cuatro que fueron seleccionados para el Informe Nacional Voluntario del Uruguay presentado en 2019 a Naciones Unidas (PRESIDENCIA DE LA REPÚBLICA, 2019). Para el ejercicio realizado en Tacuarembó se definió analizar por un lado el ODS 8 , referido a Trabajo decente y crecimiento económico ("Promover el crecimiento económico sostenido, inclusivo y sostenible, el empleo pleno y productivo y el trabajo decente para todos".) ${ }^{6}$ La decisión se

\footnotetext{
${ }^{6}$ Este ODS plantea metas específicas: 8.1 Mantener el crecimiento económico per cápita de conformidad con las circunstancias nacionales y, en particular, un crecimiento del producto interno bruto de al menos el 7\% anual en los países menos adelantados; 8.2 Lograr niveles más elevados de productividad económica mediante la diversificación, la modernización tecnológica y la innovación, entre otras cosas centrándose en los sectores con gran valor añadido y un uso intensivo de la mano de obra, 8.3 Promover políticas orientadas al desarrollo que apoyen las actividades productivas, la creación de puestos de trabajo decentes, el emprendimiento, la creatividad y la innovación, y fomentar la formalización y el crecimiento de las microempresas y las pequeñas y medianas empresas, incluso mediante el acceso a servicios financieros, 8.4 Mejorar progresivamente, de aquí a 2030, la producción y el consumo eficientes de los recursos mundiales y procurar desvincular el crecimiento económico de la degradación del medio ambiente, conforme al Marco Decenal de Programas sobre modalidades de Consumo y Producción Sostenibles, empezando por los países desarrollados; 8.5 De aquí a 2030, lograr el empleo pleno y productivo y el trabajo decente para
} 
justifica por la vinculación de este ODS con el perfil de las acciones y metas de la MDL como ámbito de concertación abocado a la promoción del desarrollo económico local, así como de las instituciones que componen la Mesa.

Complementando el análisis del ODS 8 , con fuertes implicancias económicoproductivas y sociales, se seleccionó por otra parte el ODS 13 referido a Acción por el clima ("Adoptar medidas urgentes para combatir el cambio climático y sus efectos"), que a su vez contempla una serie de metas específicas. ${ }^{7}$ Para justificar dicha decisión se tuvieron en cuenta los impactos del cambio climático sobre el funcionamiento de los agroecosistemas con su consabido efecto sobre las actividades productivas de la región Noreste.

\section{Estrategia metodológica}

La contextualización precedente pone de manifiesto las disparidades territoriales del Uruguay, focalizando la situación del departamento Tacuarembó inserto en un contexto regional particular. La heterogeneidad territorial señalada representa claramente un desafío para Uruguay de cara al cumplimiento de los ODS, lo que justifica una mirada crítica que asuma la existencia de brechas internas.

El EFI desarrollado durante el segundo semestre de 2019 se planteó el objetivo de contribuir al conocimiento y problematización de los ODS, en particular en lo relativo al impacto de los temas de la agenda global en el territorio de

todas las mujeres y los hombres, incluidos los jóvenes y las personas con discapacidad, así como la igualdad de remuneración por trabajo de igual valor; 8.6 De aquí a 2020, reducir considerablemente la proporción de jóvenes que no están empleados y no cursan estudios ni reciben capacitación, $\mathbf{8 . 7}$ Adoptar medidas inmediatas y eficaces para erradicar el trabajo forzoso, poner fin a las formas contemporáneas de esclavitud y la trata de personas y asegurar la prohibición y eliminación de las peores formas de trabajo infantil, incluidos el reclutamiento y la utilización de niños soldados, y, de aquí a 2025, poner fin al trabajo infantil en todas sus formas (NACIONES UNIDAS, 2015). Disponible en: https://www.un.org/sustainabledevelopment/es/economic-growth/ Acceso: 24/11/2019.

7 Este ODS plantea metas específicas: 8.1 Mantener el crecimiento económico per cápita de conformidad con las circunstancias nacionales y, en particular, un crecimiento del producto interno bruto de al menos el 7\% anual en los países menos adelantados; 8.2 Lograr niveles más elevados de productividad económica mediante la diversificación, la modernización tecnológica y la innovación, entre otras cosas centrándose en los sectores con gran valor añadido y un uso intensivo de la mano de obra, 8.3 Promover políticas orientadas al desarrollo que apoyen las actividades productivas, la creación de puestos de trabajo decentes, el emprendimiento, la creatividad y la innovación, y fomentar la formalización y el crecimiento de las microempresas y las pequeñas y medianas empresas, incluso mediante el acceso a servicios financieros, 8.4 Mejorar progresivamente, de aquí a 2030, la producción y el consumo eficientes de los recursos mundiales y procurar desvincular el crecimiento económico de la degradación del medio ambiente, conforme al Marco Decenal de Programas sobre modalidades de Consumo y Producción Sostenibles, empezando por los países desarrollados; 8.5 De aquí a 2030, lograr el empleo pleno y productivo y el trabajo decente para todas las mujeres y los hombres, incluidos los jóvenes y las personas con discapacidad, así como la igualdad de remuneración por trabajo de igual valor; 8.6 De aquí a 2020, reducir considerablemente la proporción de jóvenes que no están empleados y no cursan estudios ni reciben capacitación, $\mathbf{8 . 7}$ Adoptar medidas inmediatas y eficaces para erradicar el trabajo forzoso, poner fin a las formas contemporáneas de esclavitud y la trata de personas y asegurar la prohibición y eliminación de las peores formas de trabajo infantil, incluidos el reclutamiento y la utilización de niños soldados, y, de aquí a 2025, poner fin al trabajo infantil en todas sus formas (Naciones Unidas, 2015). Disponible en: https://www.un.org/sustainabledevelopment/es/economic-growth/Acceso: 24/11/2019. 
Tacuarembó. Según los lineamientos de la UDELAR con la denominación de Espacio de Formación Integral se hace referencia a iniciativas que buscan integrar las tres funciones universitarias (enseñanza, investigación y extensión) a partir de un núcleo de enseñanza y buscando incorporar la perspectiva interdisciplinaria como forma de aproximación a la realidad social. Para la realización de la experiencia se efectuó en primer término una revisión bibliográfica y se tuvieron en cuenta antecedentes de otros abordajes en el análisis de la localización de los ODS en los territorios del Uruguay, en particular el ya mencionado Informe Diagnóstico del Departamento de Tacuarembó realizado en 2019 con apoyo de la OPP y el PNUD.

Tomando como insumo los datos secundarios del mencionado diagnóstico centrado en la cuantificación de las iniciativas del gobierno departamental, el proyecto del EFI adoptó una estrategia de relevamiento que busca incorporar como datos primarios las visiones de actores de diferentes instituciones de distintos niveles gubernamentales, así como de actores de la sociedad civil, el ámbito privado y la academia, que además buscan articularse en un espacio compartido de concertación con el cometido de la promoción del desarrollo. La implementación de esta etapa del proyecto implicó en primera lugar una instancia de formación en el marco de la TED, cumpliendo con los cometidos de enseñanza. A partir de ello, asumiendo la función de extensión se realizaron talleres que fueron moderados por los estudiantes, que además asumieron por grupos los roles de anotador y de observador no participante, realizando el registro de las dos sesiones de discusión que funcionaron en paralelo. Como talleristas se contó con la participación de dos referentes de la Dirección PRODEMA de la IDT, de la referente de la Unidad de Vinculación del INIA, de una referente de la ONG CLAEH, de una referente de la Agencia de Desarrollo, de un referente territorial del MGAP, de la referente regional de la DINAPYME, de un referente de la Universidad del Trabajo del Uruguay (UTU) y Polo Tecnológico de Tacuarembó, una referente del movimiento de los trabajadores PIT-CNT y de tres docentes universitarios (vinculados al Departamento de Ciencias Económicas y a la Unidad de Extensión de la sede Tacuarembó de la UDELAR), además de los docentes del PEI, del IDIIS y la TED encargados de la organización de la actividad.

Con una estrategia cualitativa de investigación, este trabajo recoge los resultados del EFI, esto es, las visiones de los participantes de la MDL respecto a los avances y desafíos en torno a la consecución en particular de los ODS 8 y 13. Desde el punto de vista metodológico, con el abordaje cualitativo de este caso apunta a la identificación de los rasgos particulares o 'unicidad' (STAKES, 1999) que permita una mejor comprensión de las percepciones, así como de las dinámicas institucionales individuales y colectivas en torno a la implementación de los ODS en el departamento analizado. Por la naturaleza del enfoque cualitativo seleccionado, el proceso de investigación estuvo en primera instancia orientado a la comprensión que los participantes otorgan al problema en cuestión. En segunda instancia, a partir de las percepciones relevadas en los talleres, el análisis avanza en una caracterización de las apreciaciones de los referentes de las instituciones que integran la Mesa respecto a las implicancias de los ODS y la Agenda 2030. Asimismo, se esboza una sistematización de las principales acciones que dichas instituciones llevan a cabo y que se vinculan con las metas de cada objetivo. Dicha sistematización permite a su vez una evaluación cualitativa del rol que cumplen 
tanto las instituciones en particular, así como el esquema de gobernanza local que corporiza la MDL de cara a la consecución de los mencionados ODS. Esto permite por otra parte una contrastación dialógica con las políticas impulsadas desde los niveles nacionales en pos de los mismos objetivos.

Las preguntas disparadoras de los talleres del EFI fueron:

i) ¿De qué forma concibe los ODS?

ii) ¿Qué acciones entiende que son importantes para la localización del ODS 8/13? ¿cuáles son las que realiza su institución en relación a cada uno de ellos?

\section{Presentación de resultados}

A continuación se sistematizan los hallazgos, tematizando en primer término las percepciones de los participantes en cuanto a la naturaleza de los ODS y la nueva agenda global de desarrollo sostenible con sus implicancias para los territorios. En segundo lugar se presentan los testimonios respecto a las acciones de las instituciones de la MDL en lo tocante al ODS 8. En tercer lugar se explicitan los resultados de la deliberación sobre el ODS 13.

Visiones de los actores territoriales sobre la entidade de los ODS

En este punto se constata en forma unánime una consideración positiva en cuanto a la definición de la Agenda 2030 y los ODS como resultado de un proceso intergubernamental, aunque algunos señalan el desafío de la implementación real y efectiva de los mismos. Así, la referente del INIA identifica a los ODS con 'guías espirituales' mientras el mundo real parece ir en otra dirección: "Son un 'deber ser' pero no todos los países persiguen estos objetivos, lo que los vuelve un desafío personal e institucional". ${ }^{8}$ También destaca el consenso entre los participantes respecto al avance relativo que implican los ODS respecto a sus antecesores, los ODM: "Hay más metas y más concretas, que ayudan a dar un empuje." Sin embargo, para algunos referentes como el representante de UTU/Polo Tecnológico, la materialización de la agenda global en los territorios presenta serias dificultades para el accionar de los actores locales: "Son objetivos muy difusos, amplios y generales. Se difuminan muy rápido por falta de acciones concretas en la realidad", ${ }^{10}$ lo que es complementado por la referente del CLAEH: "Existe una brecha entre el consenso y las actividades concretas". " También la referente de INIA hace mención a la actuación de los propios actores locales, cuestionándose el efectivo cumplimiento de los ODS. ${ }^{12}$

Frente a este diagnóstico, se subraya la importancia de la difusión y el rol de los propios referentes: "Los actores son multiplicadores de información, encargados de que llegue a todos;" 13 "es fundamental la concientización y la

\footnotetext{
${ }^{8}$ Referente del INIA.

${ }^{9}$ Referente regional de DINAPYME.

${ }^{10}$ Referente de UTU/Polo Tecnológico.

${ }^{11}$ Referente de la ONG CLAEH.

${ }^{12}$ Referente de INIA.

${ }^{13}$ Referente de MIPESTAC/PRODEMA.
} 
educación”. ${ }^{14}$ Existe entre los participantes una expresa valoración positiva del EFI como instrumento para impulsar un mayor entendimiento en el territorio respecto a las metas planteadas por la Agenda 2030, donde varios participantes hacen mención de la experiencia del proyecto de prospectiva territorial en el que participó la MDL entre 2016 y 2017, ${ }^{15}$ bajo el paradigma del desarrollo humano sostenible.

A la vez se subraya la necesidad de trascender esta etapa informativa: "Además de informar y concientizar se debe trascender a la acción y a la movilización". ${ }^{16}$ En cuanto a las formas de la concreción material de las metas, existen diferentes visiones. Mientras que algunos subrayan la responsabilidad del Estado nacional ("A nivel nacional se vuelcan todos los objetivos sin ser específicos. Muy encapsulados. Lo que faltaría es el 'cómo"'), ${ }^{17}$ otros referentes subrayan la necesidad de planos complementarios centrados en las personas: "Hay que partir desde lo personal a lo institucional. Es necesario un enfoque en el individuo, pensar acciones concretas de sustentabilidad no sólo es cuestión del Estado." ${ }^{18}$ Significativamente, también se plantea la construcción colectiva de las metas planteadas: "Generar un nosotros ya que los individuos son los que cambian las instituciones y así comenzar a implementar los ODS". ${ }^{19}$

Existe asimismo conciencia de la necesidad de acciones que incluyan un espectro diverso de actores ("A los ODS los aterriza bastante el hecho de ser un consenso que plantea objetivos para cada realidad diferente. La integración del sector privado es fundamental”), ${ }^{20}$ así como de situaciones diferenciales de los individuos: "Según la situación de las personas entenderán o no los ODS. Quien padece hambre sólo piensa en trabajar para alimentarse, no necesariamente en si esto contamina o no". ${ }^{21}$

Visiones y acciones relacionadas com el ODS 8: Trabajo decente y crecimiento económico

En términos comparativos generales, los intercambios de los participantes manifiestan una vinculación más estrecha con el ODS 8 que con el ODS 13, lo que por un lado puede vincularse con el perfil de las organizaciones que participan en la MDL. Por otro lado, esta identificación con este ODS en particular puede relacionarse con el propio cometido de la Mesa como tal, que como ámbito de concertación se plantea aportar al desarrollo de política y proyectos que potencien las capacidades locales de desarrollo de las cadenas productivas, así como la

\footnotetext{
${ }^{14}$ Referente de DINAPYME.

${ }^{15}$ El proyecto “Visión 2050: Tacuarembó en la región Norte" se realizó con el apoyo de la División de Planificación de la OPP, que participó en el equipo de la gobernanza junto con investigadores de la sede Tacuarembó de la UDELAR y del INIA, referentes de la Intendencia Departamental de Tacuarembó y de la MDL. Incluyó metodologías de corte participativo que involucraron a un espectro amplio de actores gubernamentales del nivel nacional y departamental, referentes de la sociedad civil y del ámbito privado. Uno de los resultados fue un listado de iniciativas ordenadas por grado de prioridad para la consecución de las metas planteadas en los escenarios proyectados.

${ }^{16}$ Referente de INIA.

${ }^{17}$ Referente de UTU/Polo Tecnológico.

${ }^{18}$ Referente de la ONG CLAEH.

${ }^{19}$ Referente de INIA.

${ }^{20}$ Referente del PIT-CNT.

${ }^{21}$ Referente de la ONG CLAEH.
} 
promoción de la competitividad empresarial (especialmente de las PYMES) y el posicionamiento territorial.

También se evidencian diferentes focos en el trabajo respectivo de las instituciones: en particular la referente del PIT-CNT enfatiza la importancia que el movimiento de los trabajadores otorga a este ODS. Asimismo la referente del programa de apoyo a los micro y pequeños emprendedores (MIPESTAC) de la Dirección de Desarrollo del gobierno departamental subraya las implicancias territoriales de este ODS en un departamento como Tacuarembó, mientras que la referente del CLAEH menciona expresamente la perspectiva humana de la economía como principio de su acionar, que dialoga con este ODS. Los debates explicitan además el contexto territorial fuertemente marcado por la actividad agropecuaria y su vinculación con el desarrollo rural.

A continuación se sistematizan las principales líneas de acción de cada organización en relación al ODS 8: 


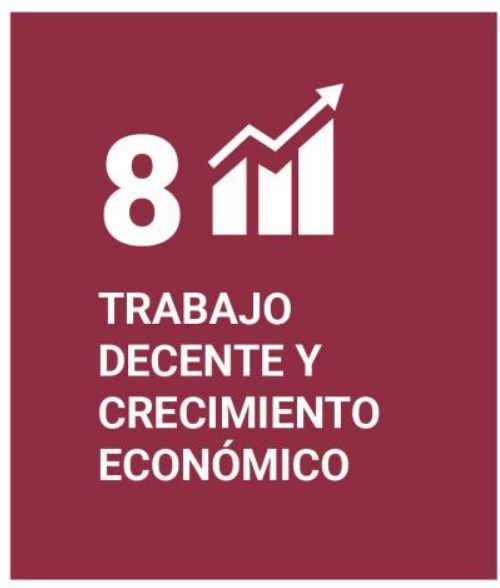

\section{PRODEMA}

Dirección de Proyectos de Desarrollo y Medioambiente de la Intendencia Departamental de Tacuarembó

- Apoyo a pequeños emprendimientos que generen empleo en el ámbito rural y urbano del departamento de Tacuarembó

- Créditos para trabajadores y productores rurales (ejemplo Fondo Rotatorio Jorge Marchesoni)

- Creación del "Fondo Joven", que otorga financiamiento

- Programa 'Tacuarembó Emprende': apoyos a diferentes tipos de emprendimientos

- Programa 'MIPESTAC': fomento de las micro y pequeñas empresas de la ciudad de Tacuarembó y nueve localidades del Interior del departamento

- Se apunta a fomentar el ecoturismo

\section{UTU}

Universidad del Trabajo del Uruguay

\section{POLO TECNOLOGICO DE TACUA-} REMBÓ

- Programa de Alfabetización Laboral

- Incorporación en la currícula de formación contenidos sobre Derecho Laboral

- Plan de Integración

- Programa de Jóvenes Emprendedores (con micro-créditos para la formación y apoyo a los emprendedores que presenten proyectos sustentables)

\section{PIT-CNT}

Representación sindical de los trabajadores

- Capacitación en derechos de los trabajadores

- Creación del Instituto Cuesta Duarte: foco en capacitación labora

- Participación en el Instituto Nacional de Empleo y Formación Profesional (INEFOP): diplomas de capacitación en áreas diversas

- Colaboración con la Universidad Católica de Uruguay: formación sindical

- Colaboración con UDELAR: cursos abiertos como los de Educación Permanente

- Programas para impulsar que se complete la escolaridad (culminación de Primaria y Secundaria)

- Algunos sindicatos desarrollan programas de capacitación (por ejemplo AEBU (Asociación de Bancarios del Uruguay)

- Defensa de la formalización del empleo

- A nivel departamental se participa del Consejo Consultivo Local (CCL) del Centro de Competitividad Empresarial (CCE)

\section{DINAPYME}

Dirección Nacional de Artesanías, Pequeñas y Medianas Empresas

- Fondo industrial para apoyar compra de equipo para las industrias

- Creación en la oficina de una Unidad de desarrollo social y de género (orientada a la inclusión y calidad del empleo)

- Acciones de comunicación desde una perspectiva de derechos

- Apoyo a acciones y proyectos empresariales, económicos y productivos)

\section{MGAP}

Ministerio de Ganadería, Agricultura y Pesca

- Desde hace dos años se lleva adelante el Programa "Campo de Oportunidades", que apunta amostrar a los jóvenes las posibilidades del trabajo en el campo
INIA

Instituto Nacional de Investigación Agropecuaria

- Acciones de investigación en pos del desarrollo económico-productivo con foco en lo agropecuario

- Acciones en pos de 'intensificación sostenible' aportando conocimiento e investigación para sostener la producción y la mano de obra rural

- Programa de investigación en producción familiar

- Plan de responsabilidad social para hijos de funcionarios para primera experiencia laboral en INIA

\section{CLAEH}

Centro Latinoamericano de Economía Humana

- Foco de sus acciones en las personas por su impronta filosófica vinculada a la Economía Humana

- Acciones orientadas a la intervención social

- Ejecutores de programas financiados por e MIDES (Ministerio de Desarrollo Social)

orientados al trabajo decente

- Apoyo a la primera experiencia laboral

- Inclusión de la perspectiva de género

- Acciones orientadas a la formalización de los emprendedores

- Acciones orientadas al desarrollo rura (educando en cuanto a derechos ciudadanos y alimentación)

- Ejecutores de programas financiados por la OPP (Oficina de Planificación y Presupuesto) orientadas a la elaboración de agendas

territoriales (con foco en reorientación laboral por ejemplo en localidad de Minas de Corrales y trabajando en conjunto con el INEFOP en capacitaciones específicas)

\section{AGENCIA DE DESARROLLO DE TACUAREMBÓ}

- Actividades relacionadas con la promoción de empresas y emprendimientos

Fuente: Elaboración propia en base a los talleres del EF

Visiones y acciones relacionadas con el ODS 13: Acción por el clima

Los intercambios de los talleristas sobre el ODS 13 evidencian menos puntos de contacto directo con la labor específica de sus instituciones, a excepción del MGAP: su referente señala en forma expresa que su organización trabaja más relacionada con el ODS 13 que con el ODS 8. Algunos participantes expresan que su 
institución no tiene acciones ni políticas concretas en materia climática. ${ }^{22}$ Con frecuencia sus intervenciones hacen referencia a programas que abordan la dimensión medioambiental en forma genérica, sin vínculo específico con el cambio climático. En esa línea de reflexión, varios actores expresan preocupación por la falta de conciencia en materia ambiental por parte de la población local en términos generales, lo que no implica desconocer algunas acciones puntuales valiosas. ${ }^{23}$

Por otra parte, existe consenso generalizado entre los participantes respecto a las implicancias económico-productivas, sociales y ambientales del calentamiento global. En lo tocante a la propia región Noreste, se menciona el contraste entre el departamento de Tacuarembó y el de Rivera: en dicho departamento desde 2017 la Dirección de Desarrollo de la Intenencia lideró el proceso de desarrollar el Plan departamental de adaptación al cambio climático para Rivera, al que se sumó Tacuarembó (LÓPEZ; LARGHERO, 2019). Por antecedentes de diversas acciones Rivera fue también seleccionado para un proyecto piloto de Movilidad Urbana Sostenible impulsado por el MIEM, el Ministerio de Vivienda, Ordenamiento Territorial y Medioambiente (MVOTMA), el Ministerio de Transporte y Obras Públicas (MTOP) y el Ministerio de Economía y Finanzas (MEF), que apunta a la incorporación de ómnibus y taxis eléctricos. ${ }^{24}$

A continuación se sistematizan las acciones mencionadas por los talleristas sobre el ODS 13:

\footnotetext{
${ }^{22}$ Referente UTU/Polo Tecnológico.

${ }^{23}$ Referente del PIT-CNT.

${ }^{24}$ El proyecto se llevará a cabo en el marco de Euroclima+ (Unión Europea), que apoya acciones que contribuyan a cumplir con el Acuerdo de París.
} 


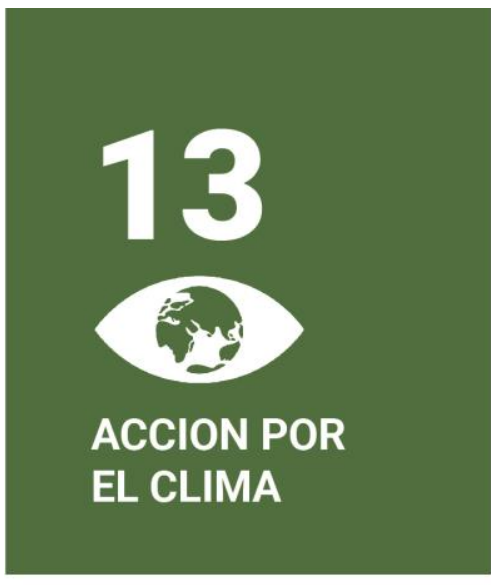

\section{PRODEMA}

Dirección de Proyectos de Desarrollo y Medioambiente de la Intendencia Departamental de Tacuarembó

- Acciones en materia de educación ambiental (por ejemplo en escuelas o Campamento anual medioambiental)

- Creación de CODEMA (Comisión Departamental Medioambiental)

- Desarrollo del Plan Departamental de Cambio Climático (en cooperación con el departamento de Rivera)

- Plan de tajamares (para resolver problemas de sequía por falta de lluvias como resultado del cambio climático)

- Apoyo para el acceso a energía solar (paneles)

- Fomento de la alimentación saludable y sostenible (frutas y verduras) a partir de producción orgánica

- Se procura apoyar la protección del monte nativo

\section{CLAEH}

Centro Latinoamericano de Economía Humana

- No tienen acciones concretas en relación a este ODS

- Consideran que no están suficientemente

informados

- Apuntan a futuro a generar una burocracia sin papeles para disminuir impactos ambientales
PIT-CNT

Representación sindical de los trabajadores

- Preocupación por las normas de seguridad laboral, también en relación a lo medioambiental como por ejemplo en el uso y manejo de agroquímicos

\section{DINAPYME}

Dirección Nacional de Artesanías, Pequeñas y Medianas Empresas

- Acciones de promoción del uso eficiente de la energía

- Fomento de la movilidad de personas sostenible (proyecto de renovación de flota de ómnibus y taxis para pasar a vehículos eléctricos)

\section{MGAP}

Ministerio de Ganadería, Agricultura y Pesca

- Creación de la Unidad de Cambio Climático del MGAP en 2001

- Lanzamiento en 2016 del proyecto "Ganaderos familiares y y cambio climático" (donación del Fondo de Adaptación, Protocolo de Kioto), que apuntó a apoyar económicamente a productores ganaderos familiares en la concreción de inversiones prediales necesarias para reducir la vulnerabilidad y aumentar la resiliencia ante el cambio y la variabilidad climática (culminando en la actualidad).

- Realización a partir de 2016 del proyecto DACC (Desarrollo y Adaptación al Cambio Climático) con financiamiento del préstamo MGAP-Banco Munidal 8099-UY.

- Presentación en septiembre de 2019 de Plan Nacional de Adaptación del Sector Agropecua rio (realizado con apoyo de FAO)

- Implementación del Plan Nacional de Riego, que ofrece medidas para apoyar a los pequeños productores frente a las sequías

\section{AGENCIA DE DESARROLLO DE TACUAREMBÓ}

- No se desarrollan actividades específicas en relación al ODS 13
INIA

Instituto Nacional de Investigación Agropecuaria

- Creación dentro de INIA de un Programa Nacional sobre Sustentabilidad

- A nivel de investigación desarrollo de alianzas internacionales en tema cambio climático (Convenio INIA-IRI, PROCISUR, GEF, Alianza Global sobre GEI)

- Proveedores de información técnico-científica para MGAP y MVOTMA (inventarios GEI Y generación de coeficientes para diseño de políticas públicas en la materia)

- Creación en1 998 en la Estación Regional La Estanzuela, como "grupo técnico" para realizar estudios sobre el clima y el cambio climático con énfasis en la implicancia sobre la actividad gropecuaria. En 2003 la Junta Directiva de INIA formaliza la creación de la Unidad de Agroclima y Sistemas de Información (GRAS)

- Llamados a través de INNOVAGRO para plataformas ambientales (incorporación de tema cambio climático)

- Líneas de investigación específicas por ejemplo aquellas relativas a la vinculación de la dimensión ambiental y la ganadería (asociadas a problemática del cambio climático), forestación (por ejemplo vinculada a plantaciones energéticas, bioenergía, etc.), monte nativo.

\section{UTU}

Universidad del Trabajo del Uruguay POLO TECNOLÓGICO DE TACUAREMBÓ

- No tiene acciones ni programas específicos sobre este ODS

- Se desarrollan algunas acciones a voluntad de los docentes

\section{- Programa de reciclado (con recipientes} separados para tirar yerba y bolsas)

- Instalación de un parque fotovoltaico

-Acciones de forestación del predio

Fuente: Elaboración propia en base a los talleres del EF

\section{Reflexiones finales y algunas perspectivas}

Como contextualización de los hallazgos del EFI cabe establecer un diálogo con la percepción acerca de la situación de los dos ODS a nivel nacional, para identificar posibles coincidencias o clivajes respecto a las visiones territoriales. Dicha contrastación puede contribuir a la complejización del análisis integral de los avances y desafíos constatados. Como visión sintética de la situación nacional cabe remitirse al citado Informe Nacional Voluntario 2019 (PRESIDENCIA DE LA REPÚBLICA, 2019) elaborado por Uruguay en cumplimiento de los compromisos de reportar cada año a Naciones Unidas. 
Respecto al ODS 8, el Informe 2019 menciona el significativo crecimiento económico del país durante los últimos quince años, con tasas superiores a la media histórica de los últimos 50 años del siglo XX. Se enfatiza que a diferencia de otras fases de crecimiento económico del Uruguay, en esta etapa dicha expansión se dio asociada a una mayor inclusión social y a trabajo decente: según este reporte, entre otros factores son indicativos de este proceso una importante reducción del desempleo, la mejora de los salarios reales, una destacable reducción de la pobreza y de la desigualdad de ingresos. Entre los elementos de la estrategia nacional para el desarrollo productivo y la creación de empleo se hace referencia a en particular a la política de promoción de inversiones por su duración y flexibilidad en diferentes etapas. Al mismo tiempo se enfatiza la fortaleza institucional y la articulación de políticas que desarrolló Uruguay en esta temática, que se consolida en 2017 con el surgimiento del Sistema Nacional de Transformación Productiva y Competitividad (SNTPC) (Ley 19.472). En materia de reformas estructurales, el Informe menciona también la evolución del ordenamiento jurídico y las políticas en materia laboral, la reforma y profundización del sistema de protección social, que habría superado una focalización reduccionista orientada solamente a aquellas personas con dificultades para acceder al mercado de trabajo y evolucionaría hacia un modelo garantista del derecho del trabajo en el país. Se mencionan las leyes y decretos reglamentarios sobre negociación colectiva, libertad sindical, accidentes de trabajo y enfermedades profesionales, descansos intermedios, semanal y licencia anual, jornada de trabajo, indemnización por despido y seguro de desempleo, seguro de enfermedad, salario y otros beneficios, maternidad y paternidad y negociación colectiva (PRESIDENCIA DE LA REPÚBLICA, 2019).

En cuanto a las apreciaciones de los referentes territoriales en cuanto al ODS 8 , aunque se reconoce el proceso de crecimiento experimentado por el país en los últimos años, es evidente la preocupación generalizada de los talleristas en cuanto a la necesidad de la dinamización de la economía regional, marcada por la especialización productiva en el sector primario (actividad agropecuaria con fuerte presencia de la ganadería y la forestación), así como de los servicios. En ese sentido, la dependencia de mercados externos para la producción agropecuaria conjugada con la ralentización del crecimiento durante los últimos dos años ha afectado directamente la demanda de productos y servicios ofrecidos por las empresas locales, afectando el nivel de empleo. ${ }^{25}$ Pese al accionar de organismos departamentales como PRODEMA y a tratarse de un ODS altamente reflejados en las iniciativas departamentales (OPP/PNUD, 2019), se hace evidente el peso del rezago histórico del departamento en cuanto al dinamismo productivo. Aunque se señala la potencialidad de nuevas instituciones en el territorio como el Centro de Competitividad Empresarial (CCE) radicado en Tacuarembó hace dos años con apoyo de la Agencia Nacional de Desarrollo (ANDE), los resultados todavía no se visualizan en el cercano plazo y existen preocupaciones respecto a la capacidad de

\footnotetext{
25 Según las estadísticas del 2018 del Ministerio de Trabajo y Seguridad Social (MTSS), el comercio representa el principal sector empleador para el departamento de Tacuarembó (20,39\%), seguido por la producción agropecuaria, forestal y pesca (17,47\%). Las mismas estadísticas indican que el $54 \%$ de la población trabaja en microempresas (aquellas que ocupan hasta 4 personas), seguidas con $28 \%$ por las empresas medianas (aquellas que empelan 50 personas o más).
} 
captar eventuales oportunidades vislumbradas con la radicación de la empresa UPM, de origen finlandés, en el Sur del departamento: dado el perfil de los beneficiarios atendidos por las instituciones de la MDL (micro, pequeños y medianas empresas) se hacen evidentes los problemas para entablar interacciones con una empresa del porte de UPM. Pese a reconocerse los avances en materia de legislación laboral planteados a nivel nacional, subsiste entre los participantes del EFI la preocupación respecto a la calidad del empleo ${ }^{26}$ y a lo endeble de diversos emprendimientos de corte más cercano al autoempleo y difícilmente escalables. Asimismo, los participantes subrayan la cuestión de la formación y capacitación tanto de los empresarios y emprendedores, ${ }^{27}$ así como de la mano de obra como factor central de sus programas y acciones, ya que se lo visualiza como crucial para superar los rezagos en materia de desarrollo económico-productivo en la región Noreste. Pese a la vocación productiva del territorio com foco forestal-maderera, se visualiza el desafío de la excesiva concentración en el destino celulósico del recurso, lo que afectaría además la elección de las especies plantadas a futuro, previéndose una fuerte concentración en el eucalipto en detrimento del pino (con eventual destino industrial como madera sólida).

En lo relativo a la visión desde el nivel nacional de la situación del ODS 13, el Informe Nacional Voluntario 2019 (PRESIDENCIA DE LA REPÚBLICA, 2019), señala la prioridad política que otorgó Uruguay a la acción por el clima dada la alta vulnerabilidad del país en términos económico-productivo (actividad agropecuaria, turismo en zonas costeras). Como prioridades se mencionan tanto las acciones dirigidas a disminuir la vulnerabilidad a través de la gestión de los riesgos y la adaptación, como también a las acciones de mitigación de las emisiones de los gases de efecto invernadero (GEI). El Informe destaca el esquema interinstitucional articulado en torno al Sistema Nacional de Respuesta al Cambio Climático y variabilidad (SNRCC) hace diez años, lo que fomentó la integración progresiva del cambio climático en las políticas públicas con una estrategia de desarrollo sostenible, resiliente y baja en carbono, con un enfoque de derechos humanos, igualdad de género y de equidad intra e intergeneracional. Dicha estrategia se materializaría a través de la Política Nacional de Cambio Climático (PNCC) aprobada en 2017 después de un proceso participativo, al igual que a través de la preparación de la Primera Contribución Determinada a Nivel Nacional (CDN) presentada a la Convención Marco de las Naciones Unidas sobre el Cambio Climático (CMNUCC), así como cuatro Comunicaciones Nacionales y dos Informes Bienales de Actualización. En vinculación con los niveles territoriales el Informe menciona la creación del Sistema Nacional de Emergencias (SINAE), fortaleciendo a los gobiernos departamentales para la atención de las emergencias causadas por fenómenos de origen climático. También se hace alusión a mejoras en la educación, la

\footnotetext{
${ }^{26}$ Según datos del Observatorio Territorial del Uruguay (OTU) de la OPP la proporción de personas empleadas en situación de informalidad sin registro en la seguridad social en el departamento de Tacuarembó en el período 2013-2017 es mayor a la media nacional, aunque en los últimos años ha decrecido, pasando del $37 \%$ al $33 \%$ de personas no registradas.

27 Según estadísticas del MTSS del 2018, el 54,75 de la población del departamento tiene educación Secundaria (siendo la media nacional el 55,5\%), mientras que el 33,9\% realizó la educación Primaria (media nacional 21,4\%). En contraste, el porcentaje de población con educación terciaria o universitaria es del 10,8\% (media nacional 22,8\%)
} 
sensibilización y la capacidad humana e institucional vinculada a la mitigación y la adaptación al fenómeno. Se alerta respecto a desafíos de mitigación (como la reducción en intensidad de emisiones de GEI planteadas en la Primera CDN, el mantenimiento del stock de carbono en el monte nativo y en las plantaciones, la disminución de emisiones por mejoras de la movilidad eléctrica y la ampliación de tecnologías de tratamiento de residuos). Respecto a adaptación entre los desafíos se menciona la consolidación de un Sistema Integral de Alerta Temprana (SIAT).

En contraste con los avances señalados desde el nivel nacional, las percepciones sobre el ODS 13 por parte de la mayoría de los referentes participantes del EFI ponen en evidencia un menor conocimiento e involucramiento de las instituciones en materia de cambio climático, aunque se reconocen expresamente los efectos económico-productivos, sociales y ambientales del fenómeno. En algunos casos se desconocen los avances en el diseño e implementación del esquema de gobernanza climática en torno del SNRCC y no se identifican a la interna de los organismos territoriales acciones específicas frente a la problemática. Una clara excepción está dada por las instituciones vinculadas a la investigación como el INIA o la UDELAR, así como por el MGAP. Los intercambios durante los talleres aluden a preocupaciones generales de los participantes en relación a problemáticas ambientales, con mayor o menor vinculación con la temática específica del ODS 13. Se hace mención a diferentes planos de posibles intervenciones donde con frecuencia el énfasis recae en la necesidad de la concientización a nivel individual, desdibujando posibles intervenciones de las instituciones locales. Algunos participantes desconocen el reciente proceso de elaboración del Plan departamental de adaptación al cambio climático liderado por el departamento de Rivera y al que adhirió Tacuarembó, así como tampoco están al tanto del proyecto piloto de Movilidad Urbana Sostenible impulsado por el MIEM en Rivera.

Para concluir puede decirse que en términos sustantivos la realización del EFI sobre localización de los ODS en Tacuarembó subraya la importancia de seguir promoviendo la instalación del tema en la agenda de las instituciones radicadas en el territorio como forma de superar brechas de información y como forma de promover la integralidad de las acciones tanto dentro de las instituciones así como a nivel de las intervenciones de dichas organizaciones en el departamento. Los intercambios evidencian además grados heterogéneos de avance en los distintos ODS. Un hallazgo significativo de la experiencia del EFI fue el reconocimiento por parte de los participantes de la necesidad de acciones concertadas que superen la inmediatez de la agenda cotidiana de las organizaciones, identificando a la MDL como un ámbito pertinente a estos fines. Es significativa la conclusión a la que arribaron los participantes en cuanto a que la UDELAR tiene un rol a cumplir en ese sentido, impulsando el proceso también dentro de la agenda de la MDL.

En términos metodológicos puede señalarse la pertinencia de la combinación de abordajes diversos para los necesarios monitoreos del proceso de localización de Ios ODS. Cabe afirmar que para las primeras fases de diagnóstico pueden resultar útiles enfoques de corte cuantitativo como el empleado en la evaluación de las prioridades de las acciones departamentales con herramientas como el RIA. Sin embargo, para lograr una evaluación en profundidad en cuanto a grados diversos de avances en la localización de la Agenda 2030 cabe subrayar la potencialidad de 
Ios abordajes cualitativos como el propuesto para el EFI aquí analizado. Los datos primarios recogidos durante la primera etapa del proyecto a través de los talleres presenciales representan un aporte a la identificación de las concepciones, propósitos y formas de acción que las instituciones consideran valiosas en relación a la Agenda 2030 y en particular en relación a los ODS 8 y 13. A la vez, desde el punto de vista de la evolución del proceso y la dinámica de la localización, el abordaje cualitativo desarrollado en el marco del EFI permitió identificar formas en que las instituciones reaccionaron al proceso de la Agenda, adecuando en algunos casos instrumentos ya existentes. Al mismo tiempo, la estrategia de relevamiento contribuyó a esbozar perfiles de acción, identificando áreas en las que las organizaciones han registrado avances o en las que todavía no han desarrollado acciones. Esto eventualmente podría tener implicancias en términos del 'agendasetting' a futuro, permitiendo el desarrollo de nuevas herramientas, ya sea a nivel de cada institución como también en el marco de la propia MDL. En ese sentido, es evidente que existe todavía espacio para que los ODS sean efectivamente integrados en la planificación tanto de los organismos gubernamentales, como así como también en las organizaciones de la sociedad civil, el ámbito privado y la propia academia.

\section{REFERENCIAS}

AROCENA, R. Conocimiento y poder en el desarrollo. Hacia estrategias democratizadoras. Montevideo: CSIC-UDELAR/Ediciones Universitarias, 2017.

AUCl. Hacia la Agenda de Desarrollo Post-2015. Explorando visiones desde América Latina. Montevideo: $\mathrm{AUCl}, 2013$.

BÁRCENA, A. La descolonización de la agenda para el desarrollo después de 2015. Hacia una asociación universal para el desarrollo. En: Ocampo, J. A. (Ed). Gobernanza global y desarrollo. Nuevos desafíos y prioridades de la cooperación internacional. México: Siglo Veintiuno Editores/CEPAL, 2015, p. 115-157.

BERTONI, R.; CASTELNOVO, C.; CUELLO, A.; FLEITAS, S.; PERA, S.; RODRÍGUEZ, J.; RUMAU, D. ¿Qué es el desarrollo? ¿Cómo se produce? ¿Qué se puede hacer para promoverlo? Construcción y análisis de problemas de desarrollo. Montevideo: UDELAR/UCUR/CSE, 2011.

CALVO, J. J. et al. Atlas Sociodemográfico y de la desigualdad del Uruguay. Las Necesidades Básicas Insatisfechas a partir de los Censos 2011. Montevideo: INE-Programa de Población-IECON-Presidencia de la Nación-MIDES-UNFPA, 2013.

CEPAL. La hora de la igualdad: Brechas por cerrar, caminos por abrir. Santiago de Chile: CEPAL, 2010.

CEPAL. Los Países de Renta Media: Un Nuevo Enfoque Basado en Brechas Estructurales. CEPAL: Santiago de Chile, 2012.

EVANS, P.; HELLER, P. Human Development, State Transformation and the Politics of the Developmental State. En: The Oxford Handbook of Transformation of the State, p. 691-713, 2015. 
FARINÓS DASÍ, Joaquín; MONTESERÍN, Obdulia; ESCRIBANO, Jaime. Cooperação Territorial e Desenvolvimento: um olhar da escala transregional e as áreas metropolitanas, rurais e turísticas. Redes (St. Cruz Sul, Online), Santa Cruz do Sul, v. 23, n. 3, p. 35-65, sep. 2018. ISSN 1982-6745. doi:https://doi.org/10.17058/redes.v23i3.12219.

GRIFFIN, K. Desarrollo humano: origen, evolución e impacto. En: IBARRA, P.; UNCETA, K. (Coord.) Ensayos sobre el desarrollo humano. Barcelona: Ed. Icaria, 2001, p. 25-40.

GLOBAL TASKFORCE OF LOCAL AND REGIONAL GOVERNMENTS. Guía para la localización de los ODS: Implementación y monitoreo subnacional. $2^{\text {nd }}$. World Assembly towards HABITAT III, 2016.

KUZNETS, S. Modern Economic Growth: Findings and Reflections. Lecture to the memory of Alfred Nobel, 1971.

LÓPEZ, N.; LARGHERO, S. Avance del Plan Departamental de Adaptación al Cambio Climático para Rivera y Tacuarembó. Rivera: INDRA /NATIVA / IDR /IDT / SNRCC / AECID |AUCl, 2019.

MAX-NEEF, M. Desarrollo a escala humana. Conceptos, aplicaciones y algunas reflexiones. Montevideo: Editorial Nordan-Comunidad, 1993.

MDL. Plan Estratégico 2015-2017. Tacuarembó: ADT / UDELAR/CUT / OPP/UMC/ INIA / IDT / AET/ CLAEH / INEFOP / MIEM / Foro de la madera / PIT-CNT / MIDES / PDP, 2015.

MEADOWS, D.; MEADOWS, D. L.; RANDERS J.; BEHRENS, W. W. The limits to Growth. A Report for the Club of Rome's Project on the Predicament of Mankind. New York: Universe Books, 1972.

OJEDA MEDINA, T. El rol estratégico de los gobiernos locales y regionales en la implementación de la Agenda 2030: experiencias desde la cooperación Sur-Sur y triangular. Oasis, N. 31, p. 9-29, 2020.

OPP/PNUD. Informe Diagnóstico - Departamento de Tacuarembó. Montevideo: OPP/PNUD, 2019.

OTU/OPP. Índice de Desarrollo Humano por departamento. Síntesis metodológica y de resultados. Montevideo: OPP, 2018.

PRESIDENCIA DE LA REPÚBLICA. ODS. Informe Nacional Voluntario - Uruguay 2017. Montevideo: Presidencia de la República, 2017.

PRESIDENCIA DE LA REPÚBLICA. ODS. Informe Nacional Voluntario - Uruguay 2019. Montevideo: Presidencia de la República, 2019.

RIVERO ILLIA, M. Introducción. Cooperación internacional para el desarrollo multidimensional. En: AUCI. La cooperación internacional para el desarrollo del Sur. Una visión desde Uruguay. Montevideo: AUCI/Presidencia de la República, 2014, p. 15-19.

RODRÍGUEZ MIRANDA, A.; MARTÍNEZ RODRÍGUEZ, C. Índice de Desarrollo Regional y Especialización Productiva. Tacuarembó. Montevideo: ANDE /IECON-FCEA-UDELAR, 2019a. 
RODRÍGUEZ MRANDA, A.; MARTÍNEZ RODRÍGUEZ, C. Índice de Desarrollo Regional y Especialización Productiva. Rivera. Montevideo: ANDE /IECON-FCEA-UDELAR, 2019b.

RODRÍGUEZ MIRANDA, A.; MARTÍNEZ RODRÍGUEZ, C. Índice de Desarrollo Regional y Especialización Productiva. Cerro Largo. Montevideo: ANDE /IECON-FCEA-UDELAR, 2019c.

ROSTOW, W. W. The Stages of Economic Growth. A Non-Communist Manifesto. London: Cambridge University Press, 1960.

SANAHUJA, J. A. La Agenda 2030 de desarrollo sostenible: de la cooperación Norte-Sur al imperativo universalista del desarrollo global. Gaceta sindical 2, 2016.

SEERS, D. The Meaning of Development. Revista Brasileira de Economia. v. 24, n. 3, p. 2950, 1970.

SERRA BORSATTO, R.; ANTUNES JUNIOR, W.F; FERREIRA SOUSA-ESQUERDO, V. Território, arranjos institucionais e os desafios para a governança territorial: apontamentos doTerritório Sudoeste Paulista (SP). REDES: Revista do Desenvolvimento Regional, v. 25 , N3, p. 940-961, 2020.

SEN, A. Desarrollo y libertad. Barcelona: Planeta, 2000.

STAKE, R. Investigación con estudios de caso. 2da. edición. Madrid: Morata, 1999.

UL HAQ, M. Reflections on Human Development. Oxford University Press. Primera edición, 1996.

Amalia Margarita Stuhldreher. Licenciada en Relaciones Internacionales (Universidad del Salvador, Argentina). Doctora en Ciencia Política, Mención en Sociología y Ciencias de la Comunicación (Universidad de Mainz, Alemania). Profesora en régimen de Dedicación Total del Instituto de Desarrollo Sostenible, Innovación e Inclusión Social (IDIIS), sede Tacuarembó de la Universidad de la República (UDELAR).E-mail: astuhldreher@hotmail.com

Como citar: STUHLDREHER, Amalia Margarita. Avances y desafíos del desarrollo sostenible en Uruguay y sus implicancias territoriales. Una mirada a la localización de los ODS en Tacuarembó. Redes (St. Cruz Sul, Online), Santa Cruz do Sul, v. 25, p. 1652-1675, nov. 2020. doi:https://doi.org/10.17058/redes.v25i4.14555. 